\title{
Gambaran Klinis dan Laboratorium Retinoblastoma
}

\author{
Nelly Rosdiana \\ Bagian Anak Fakultas Kedokteran Universitas Sumatera Utara/RS.H.Adam Malik Medan
}

Latar belakang. Retinoblastoma adalah tumor endoocular pada mata yang mengenai syaraf embrionik retina,bisa terjadi unilateral atau bilateral. Retinoblastoma bisa terjadi intraokular atau menyebar keluar mata dan ekstraokular. Gejala klinis bervariasi sesuai stadium penyakit saat datang. Pemeriksaan yang penting untuk diagnosis adalah pemeriksaan mata dengan Opthalmoscopy indirect, USG, CT scan, dan MRI. Pemeriksaan-pemeriksaan sangat berguna untuk mengevaluasi nervus optikus, orbital, keterlibatan sistem saraf pusat, dan adanya kalsifikasi intraokular.

Tujuan. Menilai gambaran klinis dan laboratorium retinoblastoma unilateral dan bilateral pada anak.

Metode. Penelitian retrospektif dari data rekam medis pasien retinoblastoma yang dirawat sejak awal Januari 2005-31 Desember 2009 di Bagian Anak RS H. Adam Malik, Medan.

Hasil. Pada periode lima tahun didapatkan 61 pasien Retinoblastoma, 53 kasus unilateral dan 8 bilateral. Rerata usia 3,2 (1,98) tahun pada unilateral dan 3,5 (3,50) tahun pada bilateral. Lama gejala 3,5 (3,56) bulan untuk unilateral dan 2,1 $(1,64)$ bulan pada bilateral. Keluhan utama yang ditemukan adalah mata menonjol (proptosis) 40 kasus $(54,1 \%$ dan 11,4\%). Pemeriksaan laboratorium didapati anemia ringan rerata $\mathrm{Hb}$ $(10,7 \pm 2,04)$ pada unilateral dan $(10,7 \pm 1,29)$ pada bilateral, nilai leukosit didapati $(9806,5 \pm 3208,4) / \mathrm{mm}^{3} \mathrm{dan}$ $12,245,0 \pm 9208,6 / \mathrm{mm}^{3}$, jumlah trombosit didapati $(411,957,0 \pm 183,951,1) / \mathrm{mm}^{3} \mathrm{dan}(458,500,0 \pm 134,040,2) /$ $\mathrm{mm}^{3}$, dan status gizi $68,8 \%$ masih baik (35 kasus Unilateral dan 7 kasus bilateral).

Kesimpulan. Pada retinoblastoma unilateral dan bilateral gambaran klinis proptosis, anemia ringan dan status gizi masih baik saat pasien datang pertama kalinya ke rumah sakit. Sari Pediatri 2011;12(5):319-22.

Kata kunci: retinoblastoma, gambaran klinis, laboratorium.

$\mathrm{R}$ etinoblastoma (RB) adalah tumor endoocular pada anak yang mengenai syaraf embrionik retina. ${ }^{1}$ Merupakan tumor ganas primer intraokular akibat dari transformasi

Alamat korespondensi:

Dr. Nelly Rosdiana, Sp.A. Divisi Hematologi-Onkologi. Bagian Ilmu Kesehatan Anak FK-USU/RS.H.Adam Malik Medan. Jln Bungalau 17 Medan. Telp.: 061-8361721/Fax : 061-8365663.E-mail: nelly_hemato@ yahoo.com keganasan sel primitif retina sebelum berdiferensiasi. ${ }^{2}$ Insidens retinoblastoma rata-rata 1/20000 kelahiran hidup. Sepertiga dari kasus terjadi bilateral. Laki-laki dan perempuan dapat terkena dan tidak dipengaruhi oleh ras. ${ }^{3.4}$ Sebagian besar kasus retinoblastoma di Amerika Serikat terdiagnosis sejak tumor masih di intraokular tanpa invasi lokal atau metastasis jauh. Di negara berkembang, diagnosis sering dibuat setelah penyakit menyebar keluar mata dan ekstraokular. ${ }^{5}$ 
Gejala retinoblastoma bervariasi sesuai stadium penyakit saat datang, dapat berupa leukoria, strabismus, mata merah, nyeri mata yang disertai glaucoma dan visus menurun. Retinoblastoma dapat terjadi secara familial dan sporadik. Hanya 6\%-10\% pasien yang mempunyai riwayat familial. Pemeriksaan yang sangat penting untuk diagnosis adalah pemeriksaaan mata dengan oftalmoskopi dan penekanan sklera oleh ahli mata yang berpengalaman. ${ }^{6}$ Penelitian dilakukan untuk menilai gambaran klinis dan laboratorium pasien retinoblastoma unilateral dan bilateral saat awal dirawat di Bagian Anak RS.H. Adam Malik Medan.

\section{Metode}

Penelitian retrospektif dilakukan pada seluruh anak retinoblastoma yang berobat ke Divisi HematologiOnkologi Departemen Ilmu Kesehatan Anak RSHAM Medan periode awal Januari 2005- 31 Desember 2009. Data diambil dari rekam medis pasien dan dikelompokkan berdasarkan umur, jenis kelamin, lokasi tumor (uni/ bilateral), riwayat keluarga dengan retinoblastoma, status gizi, dan pemeriksaan laboratorium darah. Hasil aspirasi sumsum tulang dan pemeriksaan lumbal punksi. CT scan untuk melihat evaluasi sistemik (metastase tumor). Diagnosis retinoblastoma ditegakkan berdasarkan anamnesis keluhan pada mata seperti leukoria, strabismus, mata merah, mata menonjol (proptosis), pemeriksaan fisis, dan pemeriksaan penunjang seperti USG dan CT scan orbita. Analisis statistik yang digunakan adalah uji chi-kuadrat, uji t dengan menggunakan SPSS for Window 11.5

\section{Hasil}

Selama periode bulan Januari 2005 sampai Desember 2009 didapati 67 pasien retinoblastoma yang datang ke RS H. Adam Malik, 6 pasien telah dianalisis karena data tidak lengkap, $31(50,8)$ laki-laki dan $30(49,1)$ perempuan. Terdapat 53 pasien dengan retinoblastoma unilateral dan 8 pasien bilateral, 2 pasien dengan riwayat keluarga retinoblastoma. Usia rerata pasien 3,2 $(1,98)$ tahun pada unilateral dan 3,5(3,50) tahun pada kelompok bilateral. Keluhan terbanyak dengan mata menonjol (proptosis) 33(54,1) kasus pada unilateral dan $7(11,4)$ kasus pada bilateral. Sedang keluhan bintik putih $13(21,3)$ kasus pada kelompok unilateral. Pemeriksaan CT scan orbita dilakukan pada $39(63,9)$ pasien. Pemeriksaan aspirasi sumsum tulang dilaksanakan pada $38(62,2)$ kasus. Pemeriksaan lumbal pungsi hanya dilaporkan pada $2(3,3)$ kasus pada kelompok unilateral. Nilai kadar hemoglobin 10,7 $(2,04) \mathrm{g} / \mathrm{dl}$ pada unilateral dan $10,7(1,29) \mathrm{g} / \mathrm{dl}$ pada bilateral, leukosit 9806 $(3208) / \mathrm{mm}^{3}$ pada unilateral dan $12.245(9208) / \mathrm{mm}^{3}$ pada bilateral, sedang hasil trombosit didapati 411.957 (183.951)/ $\mathrm{mm}^{3}$ pada unilateral dan 458.500 (134.040)/ $\mathrm{mm}^{3}$ pada bilateral. Sebagian besar kasus mempunyai gizi baik $11(18,0)$ kasus pada unilateral dan $2(3,2)$ kasus pada kelompok bilateral dan gizi cukup $24(39,3)$ kasus dan $5(8,1)$ kasus pada uni dan bilateral retinoblastoma. Karakteristik pasien tertera pada Tabel 1 dan Tabel 2. Tidak dijumpai perbedaan signifikan pada kelompok jenis kelamin, rerata usia, gambaran klinis, pemeriksaan laboratorium darah, CT scan, BMP, dan status gizi.

Sebagian besar pasien mengalami pengobatan dengan kemoterapi.

Tabel 1. Karakteristik pasien retinoblastoma

\begin{tabular}{lccc}
\hline Karekteristik & Unilateral & Bilateral & Total \\
\hline Jenis kelamin, $\mathrm{n}$ & & & \\
$\quad$ Laki-laki & 28 & 3 & 31 \\
$\quad$ Perempuan & 25 & 5 & 30 \\
Riwayat keluarga & - & 2 & 2 \\
Umur, tahun, rerata \pm SB & $3,2 \pm 1,98$ & $3,5 \pm 3,50$ & $3,3 \pm 2,30$ \\
Lama gejala, bulan, rerata \pm SB & $3,5 \pm 3,64$ & $2,1 \pm 1,64$ & $3,4 \pm 3,75$ \\
Tipe pengobatan, $\mathrm{n}$ & & & 6 \\
$\quad$ Enukleasi & 5 & 1 & 60 \\
$\quad$ Kemoterapi & 52 & 8 & 1 \\
$\quad$ Terapi radiasi & 1 & - & \\
\hline
\end{tabular}


Nelly Rosdiana: Gambaran klinis dan laboratorium retinoblastoma

Tabel 2. Gambaran klinis dan laboratorium pasien retinoblastoma

\begin{tabular}{lccc}
\hline & Unilateral & Bilateral & Total \\
\hline Keluhan datang, $\mathrm{n}(\%)$ & & & 1 \\
Mata merah & $1(1,6)$ & - & 13 \\
Bintik putih & $13(21,3)$ & - & 4 \\
Leukoria & $3(4,9)$ & $1(1,6)$ & 40 \\
Mata menonjol (proptosis) & $33(54,1)$ & $7(11,4)$ & 3 \\
Gejala lain & $3(4,9)$ & - & $10,7 \pm 1,92$ \\
Laboratorium & & & $14962,3 \pm 41652,54$ \\
Hb (g/dl), rerata $\pm \mathrm{SB}$ & $10,7 \pm 2,04$ & $10,7 \pm 1,29$ & $316786,03 \pm 173315,49$ \\
Leukosit $/ \mathrm{mm}^{3}$, rerata $\pm \mathrm{SB}$ & $9806,5 \pm 3208,40$ & $12245,0 \pm 9208,64$ & 38 \\
Trombosit, $/ \mathrm{mm}^{3}$, rerata $\pm \mathrm{SB}$ & $411957,0 \pm 183951,25$ & $458500,0 \pm 134040,24$ & 2 \\
CT scan & 32 & 7 & 13 \\
BMP & 31 & 7 & 29 \\
Lumbal pungsi & 2 & - & 13 \\
Status gizi,n(\%) & & & 6 \\
Baik & $11(18,0)$ & $2(3,2)$ & \\
Cukup & $24(39,3)$ & $5(8,1)$ & $1(1,6)$ \\
Kurang & $12(19,6)$ & - & \\
Buruk & $6(9.8)$ & & \\
\hline
\end{tabular}

$\mathrm{BMP}=$ aspirasi sumsum tulang

\section{Pembahasan}

Retinoblastoma merupakan tumor ganas primer intraokuler yang terbanyak pada anak-anak. Lebih dari 90\% kasus didiagnosis sebelum umur 5 tahun. Pada studi kami, rerata usia datang berobat 3,2 $(1,98)$ tahun pada unilateral dan 3,5 $(3,50)$ tahun pada bilateral dan lamanya muncul gejala $3,5(3,56)$ bulan untuk RB unilateral dan 2,1 $(1,64)$ bulan pada RB bilateral. Knudson ${ }^{5}$ menyatakan bahwa anak dengan retinoblastoma bilateral akan berkembang cepat pada awal usia dibandingkan dengan retinoblastoma unilateral. Gambaran klinis didapati proptosis 33 $(54,1 \%)$ pada unilateral dan $7(11,4 \%)$ pada bilateral. Di negara berkembang, retinoblastoma pada umumnya didiagnosis telah menyebar ke ekstraokuler. Pada keadaan ekstraokuler dapat dijumpai masa jaringan lunak di sekitar mata atau tumor dapat sampai ke daerah nervus optikus, yang akan berkembang ke otak dan meningens. Retinoblastoma yang tidak diobati akan tumbuh dan menimbulkan masalah pada mata menyebabkan lepasnya retina, nekrosis dan menginvasi mata, saraf penglihatan dan sistem syaraf pusat. Umumnya metastasis tumor terjadi dalam waktu 12 bulan. ${ }^{2}$ Pemeriksaan $C T$ scan orbita dilakukan pada 39 pasien RB (52,4\% pada unilateral dan 11,4\% pada bilateral). USG, CT scan, dan MRI sangat berguna untuk mengevaluasi nervus optikus, orbital, keterlibatan sistem syaraf pusat dan adanya kalsifikasi intraokuler. ${ }^{6,7}$ Pemeriksaan BMP dilakukan pada 38 pasien $(50,8 \%$ pada unilateral dan $11,4 \%$ pada bilateral). Aspirasi/biopsi sumsum tulang serta pungsi lumbal untuk pemeriksaan sitologi sangat dianjurkan apabila ada bukti penyebaran ekstraokuler atau metastase. Penyebaran bisa melalui hematogen atau limfatik, yang bisa terjadi minimal dalam 6 bulan pertama apabila tumor intraokuler tidak diobati. ${ }^{4}$

Tatalaksana RB melibatkan multidisplin ilmu oleh tim yang terdiri dari ahli onkologi anak, kanker mata, dan ahli radiologi. Hindari enukleasi dan terapi radiasi eksternal dan cendrung untuk melakukan terapi konservatif. Tujuan utama pengobatan adalah untuk meningkatkan survival rate dengan memelihara penglihatan dan tindakan penyelamatan bola mata. Saat ini terapi yang diberikan menggunakan kombinasi kemoterapi dengan terapi lokal lain. ${ }^{4}$ Dilaporkan dari 20 kasus RB dengan klinis proptosis (18 unilateral / 2 bilateral) tampak ukuran diameter tumor mengecil setelah mengikuti 2-3 siklus kemoterapi (data tidak dilaporkan). Kemoterapi bertujuan untuk mengurangi 
besaran tumor dan membuat tumor dapat diterapi secara lokal. Protokol adjuvan kemoterapi berupa vinkristin, etoposide, dan carboplatin/cisplatin, diberikan untuk 6-9 siklus. Shields ${ }^{8}$ melaporkan 35\% kasus retinoblastoma ukuran tumor akan mengecil mendekati $50 \%$ setelah pemberian kemoterapi dua siklus. Pada studi kami terdapat 6 pasien RB, 5 unilateral dan 1 bilateral yang dirujuk oleh opthalmologis yang telah dilakukan enukleasi. Hanya $17 \%$ pasien dengan retinoblastoma bilateral kedua matanya masih terlindungi. Gambaran seperti ini lebih banyak pada pasien yang memiliki riwayat keluarga, karena diagnosis bisa lebih awal. Sementara 13\% pasien dengan retinoblastoma bilateral kedua matanya sudah terkena karena penyakit intraokular yang lanjut, baik pada waktu datang pertama atau setelah gagal pengobatan lokal. ${ }^{7}$

Hasil laboratorium mendapatkan anemia ringan baik pada unilateral atau bilateral. Pada retinoblastoma yang merupakan suatu tumor padat, anemia sering dijumpai. Anemia merupakan komplikasi yang paling sering pada keganasan. Penyebab dan mekanisme anemia merupakan suatu kompleks multifaktorial Hubungan keganasan dan anemia bukan hanya oleh karena tumor saja, tapi dapat juga oleh karena produk tumor tersebut, atau berkembang sebagai hasil pengobatan tumor tersebut. ${ }^{9}$ Hasil pemeriksaan leukosit didapati rerata nilai leukosit lebih besar pada kelompok bilateral dibanding unilateral sedangkan nilai trombosit pada kedua kelompok tidak begitu berbeda. Jumlah trombosit meningkat sedikit dari nilai normal. Trombositopenia pada pasien tumor padat dapat terjadi oleh karena gangguan sumsum tulang atau oleh karena toksisitas obat sitostatik, namun jarang dijumpai pada saat kunjungan pertama. Apabila dijumpai trombositopenia tanpa keluhan klinis dan laboratorium yang berhubungan, mungkin saja oleh karena proses imunologik ${ }^{10}$ M.-z. Qiu dkk ${ }^{11}$ melaporkan bahwa insidens anemia, leukositosis, dan trombositosis pada tumor padat di Cina, bervariasi tergantung pada jenis keganasannya (2,1\%-29,2\%).

Pemeriksaan keadaan gizi, didapati pada pasien retinoblastoma pada umumnya masih baik Pasien dengan tumor padat mempunyai insidens tinggi untuk terjadinya malnutrisi, namun pada anak dengan leukemia limfoblastik akut risiko rendah, tumor padat tanpa metastase, dan pasien yang telah mengalami remisi secara umum, pasien dapat mempertahankan berat badan. Beberapa kasus dapat menjadi obesitas selama mengikuti pengobatan. ${ }^{12}$ Disimpulkan pada retinoblastoma unilateral dan bilateral, pada saat pasien datang ke rumah sakit didapati gambaran klinis proptosis, anemia ringan, dan status gizi masih baik.

\section{Daftar pustaka}

1. Chantada GL, Schyartzman E. Retinoblastoma. Dalam: Voute PA,Barret A, Stevens MCG, Carron HN, penyunting. Cancer in children: clinical management. Edisi ke 4. Oxford:2005.h. 384-95.

2. Banavali S. Evidence based management for retinoblastoma. Indian Journal of Medical \& Pediatric Oncology 2004; 25:35-45.

3. Lanzkowsky P. Retinoblastoma. Dalam: Manual of pediatric hematology and oncology. Edisi ke-4. Elsevier:2005.h.630-43.

4. Hurwitz RL, Shields CL, Shields JA, Barrios PC, Hurwitz MY, Chintagumpala MM. Retinoblastoma. Dalam: Pizzo PA, Poplack DG, penyunting. Principles and practice of pediatric oncology. Edisi ke-4. Lipincott Williams \& Wilkins;2002.h.825-46.

5. Moll AC, Imhoff SM, Van meeteren AY, Boers M. At what age could screening for familial retinoblastoma be stopped? A register based study 1945-98. Br J Ophthalmol 2000; 84:1170-2.

6. Chintagumpala M, Barrios PC, Paysse EA, Plon SE, Hurwitz R. Retinoblastoma: Review of Current management. The Oncologist 2007;12:1237-46.

7. Sutaryo, Hagung P. Retinoblastoma. Dalam: Permono B, Sutaryo, Ugrasena IDG, Windiastuti E, Abdulsalam M, penyunting. Buku ajar Hematologi-Onkologi anak. Jakarta: Badan Penerbit Ikatan Dokter Anak Indonesia; 2005.h.302-9.

8. Shields CL,Shields JA. Diagnosis and management of retinoblastoma. Cancer Control 2004;11:317-27

9. Saba HI. Anemia in cancer patient: Introduction and over view. Cancer Control Journal Maret/April 1998 Suplement. Didapat dari; http://www.moffittapps//ccj/v5ns/ article 1.html.

10. Khasraw M, Faraj H, Sheikha A. Thrombocytopenia in solid tumors. EJCMO 2010;2:89-92.

11. M.-z.Qiu. R.-h.Xu.D.-y.Ruan dkk. Incidence of anemia, leukocytosis, and thrombocytosis in patients with solid tumors in China. Tumor Biol 2010.31:633-41

12. Bechard LJ,Duggan C. Cancer Treatment. Dalam: Duggan C, Watkins JB, Walker WA, penyunting. Nutrition in Pediatrics. Edisi ke-4. BC Decker; 2008.h.607-16. 